\title{
Investigation of size dependency on lattice strain of nanoceria particles synthesised by wet chemical methods
}

\author{
Manju Kurian · Christy Kunjachan
}

Received: 19 March 2014/ Accepted: 21 August 2014/Published online: 7 October 2014

(C) The Author(s) 2014. This article is published with open access at Springerlink.com

\begin{abstract}
An investigation of the influence of synthesis conditions on the crystallite size, lattice parameter and lattice strain of ceriumdioxide nanoparticles synthesised by coprecipitation and sol-gel processes is presented. The effect of initial precursors, precipitation and calcination temperatures, aging time and molar concentrations of precursor solution on particle size and lattice parameter has been studied. The physicochemical characterisation was performed using X-ray diffraction (XRD), scanning electron microscopy (SEM), energy-dispersive X-ray analysis (EDX), and thermal analysis (TG-DTA). XRD profile indicates the presence of cubic fluorite-structured nanoceria particles. The average crystallite size of the samples determined by Debye-Scherrer formula ranges from 4.2 to $36.9 \mathrm{~nm}$. Lattice parameters vary from 5.37 to $5.44 \AA$. Lattice strain of the samples was analysed using Williamson-Hall analysis since these relate to imperfections and distortions in the crystal structure. It is found that ceria reduces strain by lattice expansion which is pronounced in lower dimensions.
\end{abstract}

Keywords Nanoceria $\cdot$ Coprecipitation $\cdot$ Sol-gel process - Lattice strain $\cdot$ X-ray diffraction $\cdot$ WilliamsonHall analysis

\section{Introduction}

Nanostructured ceria is technologically significant with respect to the bulk material due to its valence/defect

M. Kurian $(\bowtie) \cdot$ C. Kunjachan

Department of Chemistry, Mar Athanasius College,

Kothamangalam 686666, India

e-mail: manjukurian@gmail.com structure and surface to volume ratio. Applications of ceria include fields such as catalysis, oxygen sensors, electrolyte materials of solid oxide fuel cells and biomedical science [1-4]. Ceria plays a prominent role in the three-way catalysis for the control of emission of automotive exhaust gases. It has the capacity to remove soot from diesel engine exhaust and organics from aqueous waste streams [5, 6]. It also acts as an additive for combustion catalysts.

$\mathrm{CeO}_{2}$ crystallises in fluorite crystal structure, in which each $\mathrm{Ce}^{4+}$ cation is coordinated by eight nearest oxygen anions and each oxygen anion by four nearest $\mathrm{Ce}^{4+}$ cations. Loss of oxygen and/or its electrons forms oxygen vacancies or defects in the lattice. This defect results in lattice strain in crystals. The distortion may arise and change with temperature, oxygen partial pressure, doping with other ions, electrical field or surface stress. It can be explained using defect equation in Kroger-Vink notations $[7,8]$.

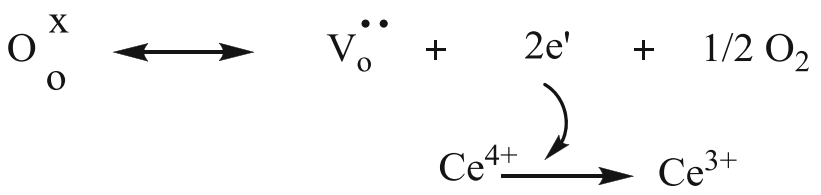

where $\mathrm{O}_{\mathrm{o}}^{\mathrm{x}}$ is the oxide ion in the lattice, $\mathrm{V}_{\mathrm{o}}^{\bullet \bullet}$ is doubly charged oxygen vacancy, $\mathrm{e}^{\prime}$ is the electron in the conduction band made up of Ce $4 \mathrm{f}$ energy states.

Because of its technological importance, synthesis of nanostructured ceria under various conditions has been experimented. Synthesis techniques include solution-based techniques such as coprecipitation [9, 10], hydrothermal [11], micro-emulsion [12], sol-gel [13, 14], solution combustion, electrochemical methods and solid-based techniques such as mechanochemical method, chemical 
vapour deposition [15] and sputtering [16]. The present work emphasises the effect of synthesis conditions on the crystallite size, lattice parameter and lattice strain on ceria nanoparticles. Ammonium cerium(IV) nitrate (CAN) and cerium(III)nitrate hexahydrate $(\mathrm{CN})$ were used as the synthetic precursors. The effect of variables such as initial precursors, temperature, aging time, molar concentrations and calcination temperature on lattice parameter and strain is also studied.

\section{Materials and methods}

All reagents used in the experiments were of analytical grade and were used without further purification. Ammonium cerium(IV) nitrate and cerium(III) nitrate hexahydrate were supplied by Aldrich Chemical Co. Inc. (St. Louis, MO, USA) and ammonia and ethylene glycol by Merck Chemicals (Mumbai, India).

Nanoceria was prepared by two different methods, viz coprecipitation techniques and sol-gel methods. In a typical coprecipitation method, dilute aqueous solution of ammonia was added dropwise to $0.1 \mathrm{M}$ of ammonium cerium(IV) nitrate/cerium(III) nitrate hexahydrate solution with magnetic stirring at ambient temperature until the precipitation was complete $(\mathrm{pH} \sim 10)$. The resulting slurry was stirred for further $2 \mathrm{~h}$, filtered off and washed several times with distilled water until it was free from anionic impurities. The obtained precipitate was oven dried at $110{ }^{\circ} \mathrm{C}$ and calcined at 400 or $700{ }^{\circ} \mathrm{C}$ for $5 \mathrm{~h}$. The same procedure was repeated using 0.2 and $0.3 \mathrm{M}$ precursor solutions for studying the effect of initial concentration. The effect of precipitation temperature was studied by varying the temperature as 50,60 and $70{ }^{\circ} \mathrm{C}$. The required amounts of cerium salts dissolved in ethylene glycol were also employed as precursor.

In sol-gel process, ammonium cerium(IV), nitrate/cerium(III) nitrate hexahydrate were dissolved in minimum amount of ethylene glycol solution with magnetic stirring and heated at $60{ }^{\circ} \mathrm{C}$ until a dried gel was obtained. The reddish brown gel on combustion yielded yellow powder of ceria. The powder was calcined at $700{ }^{\circ} \mathrm{C}$ for $5 \mathrm{~h}$ to attain crystallinity.

Phase identification of the prepared samples was recorded on a Rigaku MiniFlex 600 powder X-ray diffractometer using $\mathrm{CuK} \alpha$ radiation. The average crystallite size was determined by Scherrer equation:

$D=\frac{K \lambda}{\beta_{h k l} \cos \theta}$

where $D$ is the average crystallite size, $K$ the shape factor (0.89), $\lambda$ the wavelength of the incident X-rays (1.5418 $\AA$ ), $\theta$ the diffraction angle, and $\beta_{h, k, l}$ the full width at half maximum (FWHM) of the Bragg peak corrected using the corresponding peak in micron-sized powder. Lattice parameter ' $a$ ' was calculated from the formula:

$d_{h k l}=\frac{a}{\left[h^{2}+k^{2}+l^{2}\right]^{1 / 2}}$

where ' $a$ ' is the face-centred cubic (fcc) lattice parameter and $d_{h k l}$ is the interplanar spacing between planes with Miller indices $h, k$ and $l$.

The thermal analysis of synthesised ceria was investigated by thermo gravimetric analysis (TGA) and differential thermal analysis (DTA) using Perkin Elmer, Diamond TG/DTA instrument. The heat flow and weight change of the samples were measured in Nitrogen gas (100 ml/min) from 40 to $880{ }^{\circ} \mathrm{C}$ at a heating rate of $10{ }^{\circ} \mathrm{C} /$ min.

For SEM-EDS analysis, JEOL JSM-6390LV scanning electron microscope with JEOL JED-2300 energy-dispersive spectroscopy was employed. The accelerating voltage of electron was $20 \mathrm{kV}$.

\section{Results and discussion}

The aim of the present work is to study the effects of various synthesis variables on particle size and lattice strain in nanostructured ceria particles and hence to optimise the preparation conditions. Figures 1 and 2 represent the XRD profile of nanoceria prepared by coprecipitation using 1:1 ammonia under ambient conditions and calcined at $400-700{ }^{\circ} \mathrm{C}$, respectively. The X-ray diffractogram peaks can be indexed to cubic fluorite structure with standard JCPDS card (34-0394). Characteristic peaks of (111), (200), (220) and (311)planes of cubic-phased ceria particles are observed. For samples calcined at low temperature $\left(400{ }^{\circ} \mathrm{C}\right)$, X-ray diffraction profile (XRD) depicts broad peaks with low intensity. Average crystallite size ranges from 4.2 to $4.9 \mathrm{~nm}$. However, with samples calcined at high temperature $\left(700{ }^{\circ} \mathrm{C}\right)$, the peaks are significantly narrower with higher intensities, indicative of increase in particle size. The sharp peaks confirm the highly crystalline nature of ceria. Particle size varies in the range of $6.7-11.8 \mathrm{~nm}$. Calcination at high temperature results in rapid grain growth leading to agglomeration. This is a common observation with respect to nanoparticles [17]. Lattice parameter values are inconsistent at $400{ }^{\circ} \mathrm{C}$ with ' $a$ ' value ranging from 5.41 to $5.44 \AA$. But at high calcinations temperature, the particles have a constant ' $a$ ' value of $5.39 \AA$ (Tables 1, 2). This variation may be due to the decrease in particle size that brings about lattice strain, resulting in lattice expansion at low calcination temperature. Hence, in further studies, calcination temperature was fixed as $700{ }^{\circ} \mathrm{C}$. From the XRD data, it can also be 




Fig. 1 PXRD pattern of the nano- $\mathrm{CeO}_{2}$ calcined at $400{ }^{\circ} \mathrm{C} . a 0.1 \mathrm{M}$ CAN precursor, $b$ Ethylene glycol-mediated $0.1 \mathrm{M}$ CAN precursor, c $0.1 \mathrm{M} \mathrm{CN}$ precursor, $d$ Ethylene glycol-mediated $0.1 \mathrm{M} \mathrm{CN}$ precursor

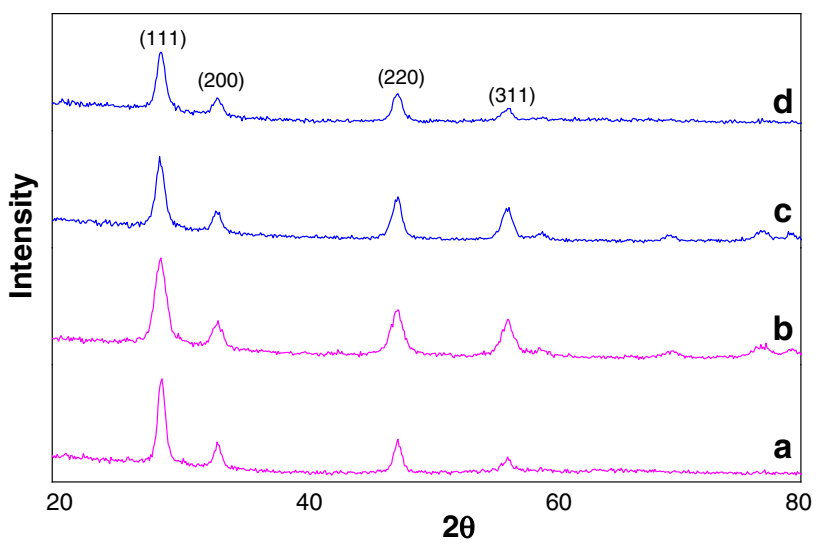

Fig. 2 PXRD pattern of the nano- $-\mathrm{CeO}_{2}$ calcined at $700{ }^{\circ} \mathrm{C} . a 0.1 \mathrm{M}$ CAN precursor, $b$ Ethylene glycol-mediated $0.1 \mathrm{M}$ CAN precursor, c $0.1 \mathrm{M}$ CN precursor, $d$ Ethylene glycol-mediated $0.1 \mathrm{M} \mathrm{CN}$ precursor

concluded that crystalline nanoceria particles of low crystallite size can be synthesised from both CAN/CN. The presence of ethylene glycol in the solution does not change the particle size and lattice parameter considerably.

Figure 3 depicts the XRD profile of nanoceria prepared by two successive steps; precipitation of cerium hydroxide by ammonia followed by $18 \mathrm{~h}$ aging before the washing step. The peaks can be ascribed to (111), (200), (220), (311) and (222) reflections of cubic-phased nanoceria. The calculated average crystallite size and lattice parameter are included in Table 3. The average crystallite sizes of samples are in the range of $11-13.1 \mathrm{~nm}$ and lattice parameter values vary from 5.41 to $5.42 \AA$. Significant aggregation of particles resulting in higher particle size was expected as a result of aging, but it was not observed in this study.
Table 1 Data from PXRD pattern of the nano- $\mathrm{CeO}_{2}$ calcined at $400{ }^{\circ} \mathrm{C}$

\begin{tabular}{lll}
\hline $\begin{array}{l}\text { Sample } \\
\text { code }\end{array}$ & $\begin{array}{l}\text { Average crystalline size, } \\
D(\mathrm{~nm})\end{array}$ & $\begin{array}{l}\text { Lattice parameter, } \\
a(\AA)\end{array}$ \\
\hline $1 \mathrm{a}$ & 4.2 & 5.41 \\
$1 \mathrm{~b}$ & 4.2 & 5.44 \\
$1 \mathrm{c}$ & 4.9 & 5.41 \\
$1 \mathrm{~d}$ & 4.2 & 5.43
\end{tabular}

(1a) 0.1 M CAN precursor, (1b) Ethylene Glycol-mediated $0.1 \mathrm{M}$ CAN precursor

(1c) $0.1 \mathrm{M} \mathrm{CN}$ precursor, (1d) Ethylene Glycol-mediated 0.1 M CN precursor

Table 2 Data from PXRD pattern of the nano- $\mathrm{CeO}_{2}$ calcined at $700{ }^{\circ} \mathrm{C}$

\begin{tabular}{lll}
\hline $\begin{array}{l}\text { Sample } \\
\text { code }\end{array}$ & $\begin{array}{l}\text { Average crystalline size, } \\
D(\mathrm{~nm})\end{array}$ & $\begin{array}{l}\text { Lattice parameter, } \\
a(\AA)\end{array}$ \\
\hline $2 \mathrm{a}$ & 6.7 & 5.39 \\
$2 \mathrm{~b}$ & 8.9 & 5.39 \\
$2 \mathrm{c}$ & 9.9 & 5.39 \\
$2 \mathrm{~d}$ & 11.8 & 5.39 \\
\hline
\end{tabular}

(2a) 0.1 M CAN precursor, (2b) Ethylene Glycol-mediated $0.1 \mathrm{M}$ CAN precursor

(2c) $0.1 \mathrm{M} \mathrm{CN}$ precursor, (2d) Ethylene Glycol-mediated 0.1 M CN precursor

Figure 4 demonstrates that the XRD pattern of $\mathrm{CeO}_{2}$ synthesised under different molar concentrations of ammonium cerium nitrate and cerium nitrate hexahydrate is depicted. The peaks are more intense and sharper as the initial concentration of the precursor solution is increased. The peaks can be indexed to cubic fluorite structure with planes (111), (200), (220), (311) and (222). Average crystallite size also increases from the range of 6.7-9.9 to 14-20.4 nm. During precipitation, nucleation occurs followed by growth and with solutions of low concentration, the nuclei form at nearly the same time. Subsequent growth of these nuclei results in the formation of particles with a narrow size distribution; whereas at high concentration, random agglomeration between particles may occur resulting in an increase in particle size. From Table 4, it can be seen that lattice parameter varies from 5.40 to $5.42 \AA$ indicating lattice expansion. This may be due to the defects or distortions formed as a result of rapid growth rate.

Figure 5 shows the XRD profile of nanoceria synthesised at various temperatures like ambient temperature, 50, 60 and $70{ }^{\circ} \mathrm{C}$. The diffraction patterns are characterised by the presence of face-centred cubic $\mathrm{CeO}_{2}$ particles oriented along the (111), (200), (220), (311) and (222) reflection planes. Particle size obtained is in the range of $6.7-15.1 \mathrm{~nm}$ 


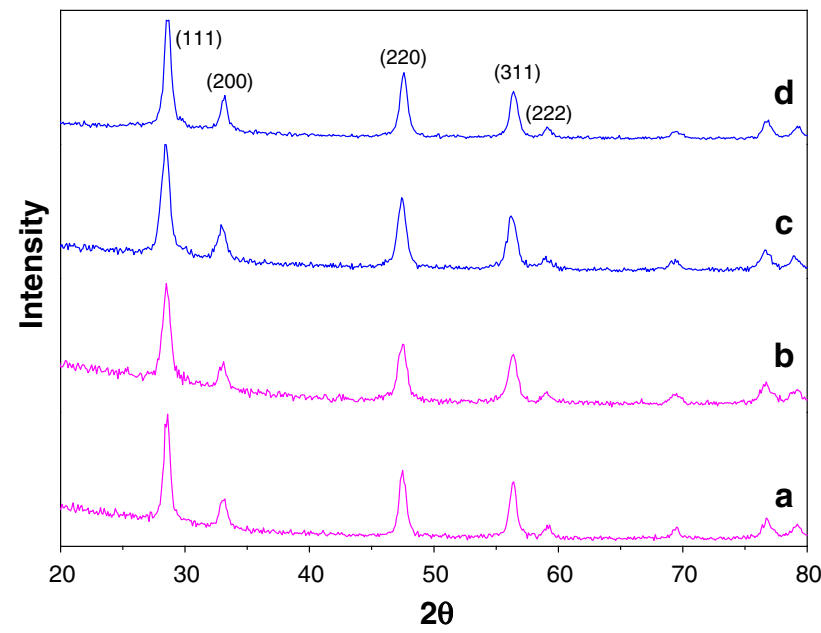

Fig. 3 PXRD pattern of the nano- $\mathrm{CeO}_{2}$ synthesised from aged cerium hydroxide solutions. $a 0.1 \mathrm{M}$ CAN precursor, $b$ Ethylene glycol-mediated $0.1 \mathrm{M}$ CAN precursor, $c 0.1 \mathrm{M} \mathrm{CN}$ precursor, $d$ Ethylene glycol-mediated $0.1 \mathrm{M} \mathrm{CN}$ precursor

Table 3 Data from PXRD pattern of the nano- $\mathrm{CeO}_{2}$ synthesised from aged cerium hydroxide

\begin{tabular}{lll}
\hline $\begin{array}{l}\text { Sample } \\
\text { code }\end{array}$ & $\begin{array}{l}\text { Average crystalline size, } \\
D(\mathrm{~nm})\end{array}$ & $\begin{array}{l}\text { Lattice parameter, } \\
a(\AA)\end{array}$ \\
\hline $3 \mathrm{a}$ & 11.0 & 5.42 \\
$3 \mathrm{~b}$ & 12.2 & 5.41 \\
$3 \mathrm{c}$ & 13.1 & 5.41 \\
$3 \mathrm{~d}$ & 12.9 & 5.41
\end{tabular}

(3a) $0.1 \mathrm{M}$ CAN precursor, (3b) Ethylene Glycol-mediated $0.1 \mathrm{M}$ CAN precursor

(3c) $0.1 \mathrm{M} \mathrm{CN}$ precursor, (3d) Ethylene Glycol-mediated 0.1 M CN precursor

and lattice parameter varies from 5.39 to $5.44 \AA$ as shown in Table 5. When temperature increases from ambient to higher, the rate of movement of the reactant molecules becomes faster and their self-assemblance increases resulting in higher particle size.

Sol-gel method was also employed for the synthesis of nanoceria in the present work. The XRD peaks shown in Fig. 6 can be indexed to cubic fluorite structure. In sol-gel process, the growth process starts with the reaction between ammonium cerium nitrate/cerium nitrate hexahydrate and ethylene glycol. Ethylene glycol is an alcohol with a pKa value of about 15 and can be oxidised to carboxylic acids such as formic acid in the presence of oxidant, CAN/CN. The cerium(IV)cation is reduced by ethylene glycol to cerium(III). The cerium(III) ion centres interact with the carboxylic group in formic acid to form cerium formate. During calcination, cerium formate is oxidised to nanostructured ceriumdioxide [18] which

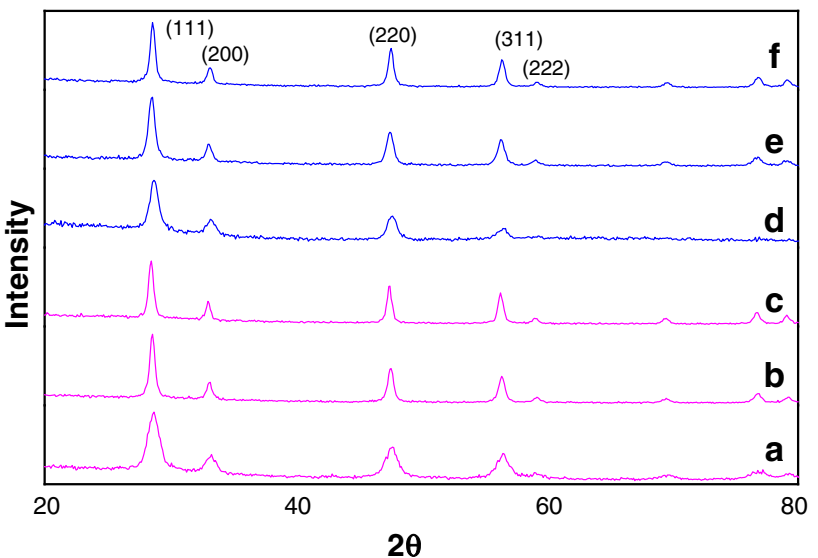

Fig. 4 PXRD pattern of the nano- $\mathrm{CeO}_{2}$ synthesised from different molar precursor solution. $a 0.1 \mathrm{M}$ CAN precursor, $b 0.2 \mathrm{M}$ CAN precursor, $c 0.3 \mathrm{M}$ CAN precursor, $d 0.1 \mathrm{M} \mathrm{CN}$ precursor, $e 0.2 \mathrm{M}$ $\mathrm{CN}$ precursor, $f 0.3 \mathrm{M} \mathrm{CN}$ precursor

Table 4 Data from PXRD pattern of the nano- $\mathrm{CeO}_{2}$ synthesised from different molar precursor solutions

\begin{tabular}{lll}
\hline $\begin{array}{l}\text { Sample } \\
\text { code }\end{array}$ & $\begin{array}{l}\text { Average crystalline size, } D(\mathrm{~nm}) \\
(\AA)\end{array}$ & $\begin{array}{l}\text { Lattice parameter, } \\
a(\AA)\end{array}$ \\
\hline $4 \mathrm{a}$ & 6.7 & 5.39 \\
$4 \mathrm{~b}$ & 17.1 & 5.41 \\
$4 \mathrm{c}$ & 14.0 & 5.42 \\
$4 \mathrm{~d}$ & 9.9 & 5.39 \\
$4 \mathrm{e}$ & 20.4 & 5.42 \\
$4 \mathrm{f}$ & 19.4 & 5.40
\end{tabular}

(4a) 0.1 M CAN precursor, (4b) $0.2 \mathrm{M}$ CAN precursor, (4c) $0.3 \mathrm{M}$ CAN precursor

(4d) $0.1 \mathrm{M} \mathrm{CN}$ precursor, (4e) $0.2 \mathrm{M} \mathrm{CN}$ precursor, (4f) $0.3 \mathrm{M} \mathrm{CN}$ precursor

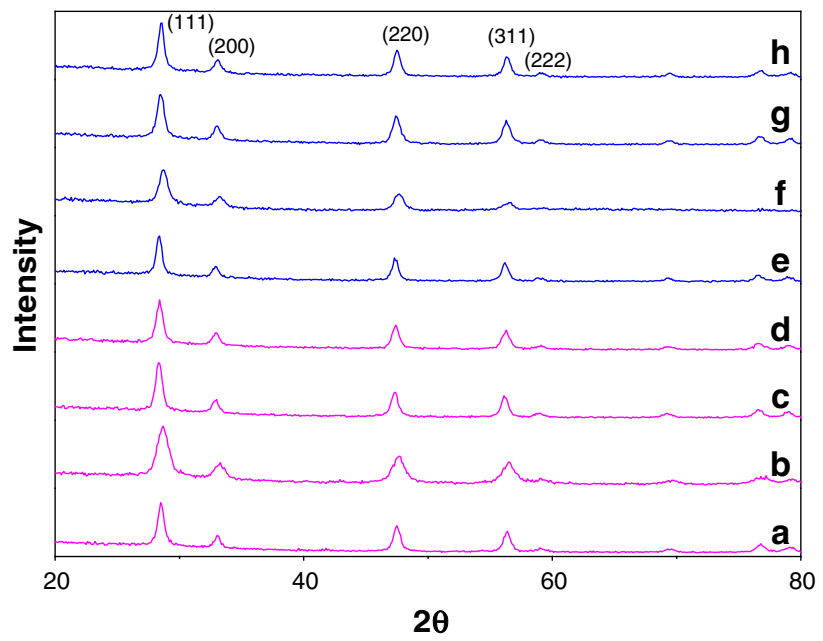

Fig. 5 PXRD pattern of the nano- $\mathrm{CeO}_{2}$ synthesised at different temperatures $a, b, c, d: 0.1 \mathrm{M} \mathrm{CAN}$ precursor at ambient temperature, 50,60 , and $70{ }^{\circ} \mathrm{C}$, respectively, $e, f, g, h: 0.1 \mathrm{M} \mathrm{CN}$ precursor at ambient temperature, 50,60 , and $70^{\circ} \mathrm{C}$, respectively 
Table 5 Data from PXRD pattern of the nano- $\mathrm{CeO}_{2}$ as a function of temperature

\begin{tabular}{lll}
\hline $\begin{array}{l}\text { Sample } \\
\text { code }\end{array}$ & $\begin{array}{l}\text { Average crystalline size, } D(\mathrm{~nm}) \\
(\AA)\end{array}$ & $\begin{array}{l}\text { Lattice parameter, } \\
a(\AA)\end{array}$ \\
\hline $5 \mathrm{a}$ & 6.7 & 5.39 \\
$5 \mathrm{~b}$ & 14.0 & 5.43 \\
$5 \mathrm{c}$ & 13.5 & 5.43 \\
$5 \mathrm{~d}$ & 15.1 & 5.44 \\
$5 \mathrm{e}$ & 9.9 & 5.39 \\
$5 \mathrm{f}$ & 13.4 & 5.42 \\
$5 \mathrm{~g}$ & 14.4 & 5.42 \\
$5 \mathrm{~h}$ & 13.7 & 5.42 \\
\hline
\end{tabular}

5a, 5b, 5c, 5d: 0.1 M CAN precursor at ambient temperature, 50, 60, and $70{ }^{\circ} \mathrm{C}$, respectively, $5 \mathrm{e}, 5 \mathrm{f}, 5 \mathrm{~g}, 5 \mathrm{~h}: 0.1 \mathrm{M} \mathrm{CN}$ precursor at ambient temperatures, 50,60 , and $70{ }^{\circ} \mathrm{C}$, respectively

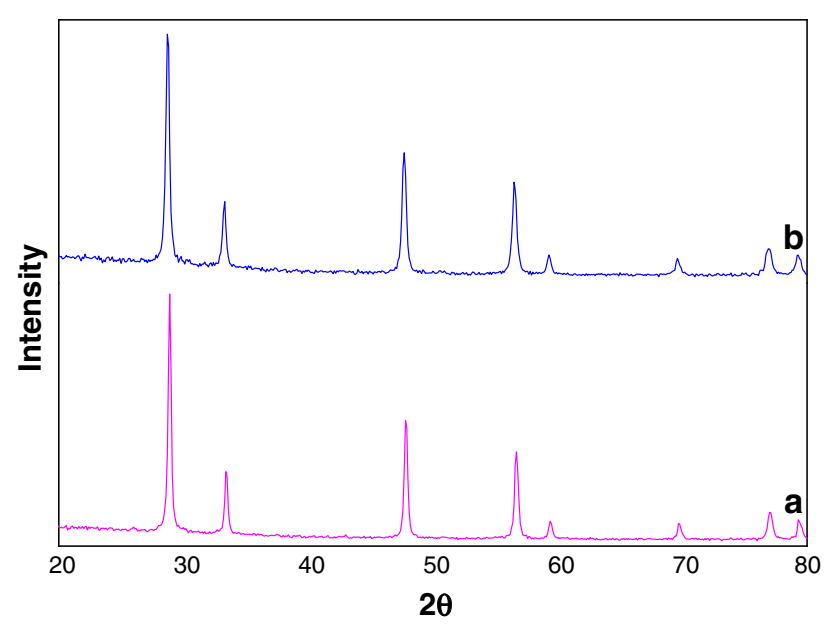

Fig. 6 PXRD pattern of the nano- $\mathrm{CeO}_{2}$ synthesised by sol-gel process. $a$ Ethylene glycol-mediated CAN, $b$ Ethylene glycolmediated $\mathrm{CN}$

Table 6 Data from PXRD pattern of the nano- $\mathrm{CeO}_{2}$ synthesised by sol-gel process

\begin{tabular}{lll}
\hline $\begin{array}{l}\text { Sample } \\
\text { code }\end{array}$ & $\begin{array}{l}\text { Average crystalline size, } \\
D(\mathrm{~nm})\end{array}$ & $\begin{array}{l}\text { Lattice parameter, } \\
a(\AA)\end{array}$ \\
\hline $6 \mathrm{a}$ & 36.8 & 5.37 \\
$6 \mathrm{~b}$ & 27.9 & 5.39 \\
\hline
\end{tabular}

(6a) Ethylene glycol-mediated CAN, (6b) Ethylene glycol-mediated $\mathrm{CN}$

enhances chances for agglomeration and hence average crystallite size was found to be 27.9 and $36.8 \mathrm{~nm}$ and lattice parameter 5.39 and $5.37 \AA$ (Table 6), respectively, for $\mathrm{CN}$ and CAN precursors indicating no significant lattice expansion.

The synthesised ceria was subjected to TG analysis before calcination. The obtained thermograms between 40 and $880{ }^{\circ} \mathrm{C}$ are shown in Fig. 7. The TGA curve for the pure ceria sample exhibits one major and two minor weight loss peaks. The major weight loss peak in the range of $40-200{ }^{\circ} \mathrm{C}$ corresponds to the loss of non-dissociative adsorbed water and water held on the surface by hydrogen bonding. The minor weight loss peak in the intermediate region is due to the loss of water held on the micropores and at high-temperature region is due to dehydroxylation of the surface. The weight loss of the sample from ambient to $873{ }^{\circ} \mathrm{C}$ is about $10 \%$. It indicates that over these temperature ranges, the cerium dioxide is thermally quite stable in terms of phase and chemical composition.

The morphology of the selected samples prepared under different conditions was investigated by scanning electron microscopy. From the SEM images (Fig. 8), it can be seen that for all the samples, the shapes are irregular. The ceria crystallites seem to aggregate to form secondary particles on the surface. Fewer voids between the aggregates were observed. Also, it can be concluded that the preparation conditions do not affect the surface morphology to a great extent. The elemental composition of the selected samples is given in Table 7 . The data show higher percentage of oxygen for samples calcined at $400{ }^{\circ} \mathrm{C}$ which decreases as the calcination temperature is raised to $700{ }^{\circ} \mathrm{C}$ indicating the escape of anions, creating vacancies.

\section{Lattice strain analysis}

Defect structure in crystals causes lattice strain, which is a quantitative measure of dislocations and crystal defects since nanoparticles reduce their strain by lattice expansion. Strain due to lattice deformation induces peak broadening in the XRD profile. Williamson-Hall analysis is a somewhat accurate method to calculate crystalline size and lattice strain. From Debye-Scherrer's formula, the full width at half maximum is

$\beta_{h k l}=\frac{K \lambda}{D \cos \theta}$

Line broadening can also be due to strain induced in crystalline powders because of imperfections and distortions quantified as.

$\beta_{h k l}=4 \varepsilon \tan \theta$

where $\varepsilon$ is the lattice strain induced in crystalline particles. Assuming that particle size and strain contribution to line broadening are independent of each other, then the observed line breadth is the sum of (1) and (2).

$\beta_{h k l}=\frac{K \lambda}{D \cos \theta}+4 \varepsilon \tan \theta$

Rearranging (3) 
Fig. 7 TGA of uncalcined ceria

Fig. 8 SEM images of ceria $0.3 \mathrm{M}$ CAN precursor $0.1 \mathrm{M}$ $\mathrm{CN}$ precursor at $70{ }^{\circ} \mathrm{C} 0.1 \mathrm{M}$ CAN precursor (calcined at $400{ }^{\circ} \mathrm{C}$ ) $0.1 \mathrm{M}$ CAN precursor (calcined at $700{ }^{\circ} \mathrm{C}$ )

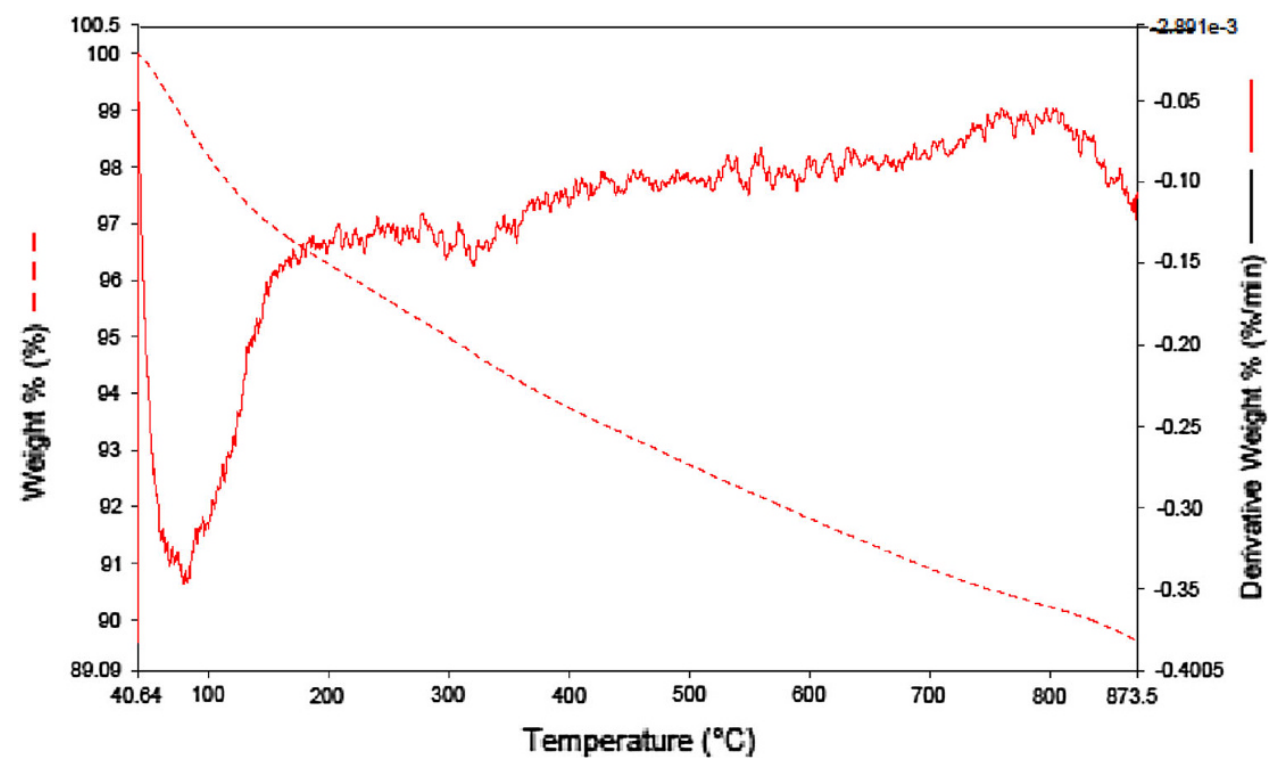

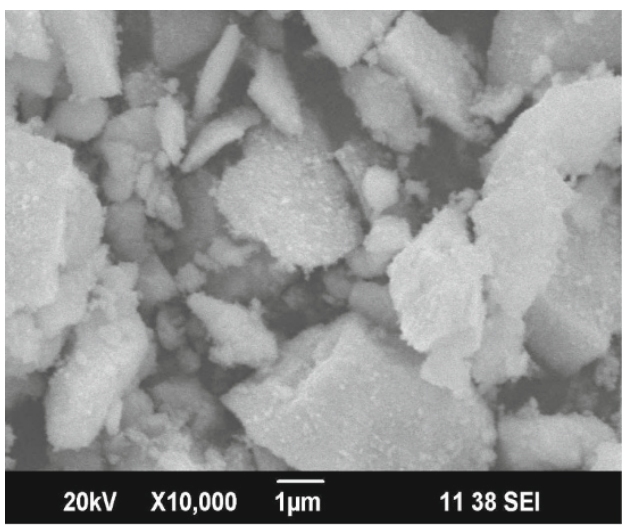

0.3M CAN pre-cursor

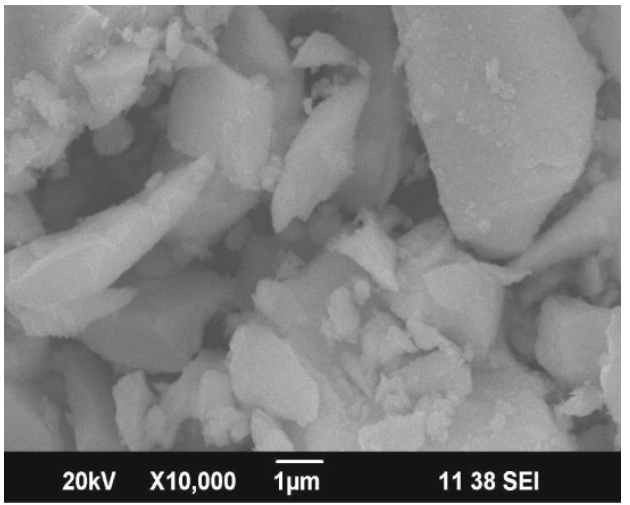

$0.1 \mathrm{M} \mathrm{CAN}$ pre-cursor (calcined at $400^{\circ} \mathrm{C}$ )

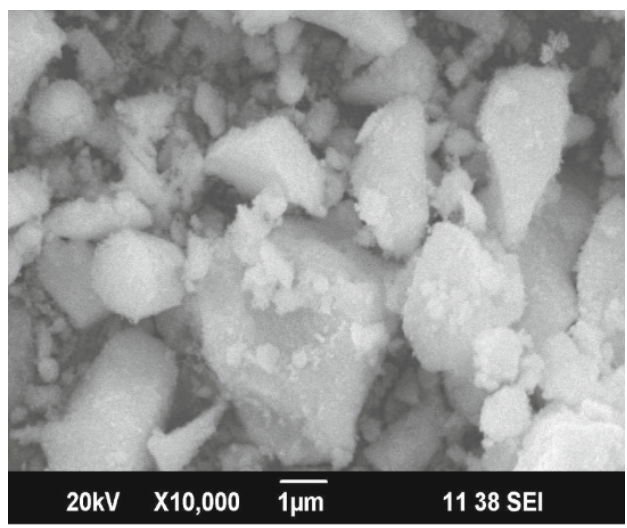

$0.1 \mathrm{M} \mathrm{CN}$ pre-cursor at $70^{\circ} \mathrm{C}$

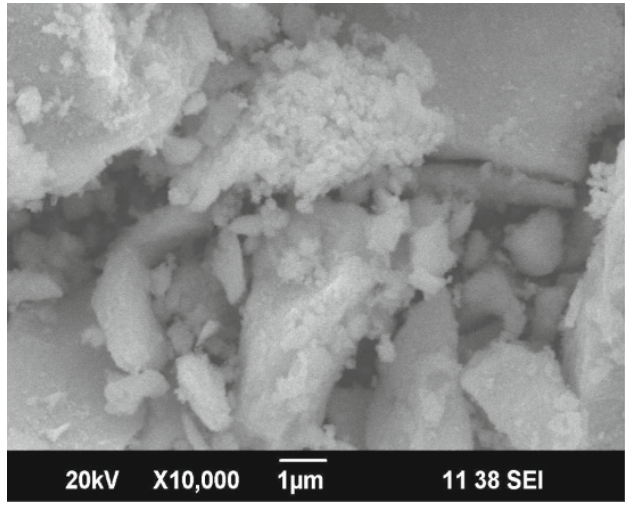

$0.1 \mathrm{M} \mathrm{CAN}$ pre-cursor (calcined at $700^{\circ} \mathrm{C}$ ) $\beta_{h k l} \cos \theta=\frac{K \lambda}{D}+4 \varepsilon \sin \theta$

Equations (3) and (4) are W-H equations [19].

Plotting $4 \sin \theta$ along $\mathrm{X}$-axis and $\beta_{h k l} \cos \theta$ along $\mathrm{Y}$-axis, a linear fit can be obtained. From the linear fit data, the slope can be interpreted as $\varepsilon$ and $D$ as intercept.
At low oxygen, partial pressure and high temperature, $\mathrm{CeO}_{2}$ releases oxygen and creates doubly charged oxygen vacancies and electrons in the $\mathrm{Ce} 4 \mathrm{f}$ energy state. The electrons formed during reduction localise on cerium converting $\mathrm{Ce}^{4+}$ to $\mathrm{Ce}^{3+}$. Ceria in the fluorite structure exhibits a few defects which releases significant levels of 
Table 7 TGA of uncalcined ceria

\begin{tabular}{lll}
\hline Sample code & Ce (Atom \%) & O (Atom \%) \\
\hline $7 \mathrm{a}$ & 26.67 & 73.33 \\
$7 \mathrm{~b}$ & 27.71 & 72.29 \\
$7 \mathrm{c}$ & 26.63 & 73.37 \\
$7 \mathrm{~d}$ & 24.56 & 75.44 \\
\hline
\end{tabular}

(7a) $0.3 \mathrm{M} \mathrm{CAN}$ precursor, (7b) $0.1 \mathrm{M} \mathrm{CN}$ precursor at $70^{\circ} \mathrm{C}$

(7c) $0.1 \mathrm{M}$ CAN precursor (calcined at $400{ }^{\circ} \mathrm{C}$ ), (7d) $0.1 \mathrm{M} \mathrm{CAN}$ precursor (calcined at $700{ }^{\circ} \mathrm{C}$ )

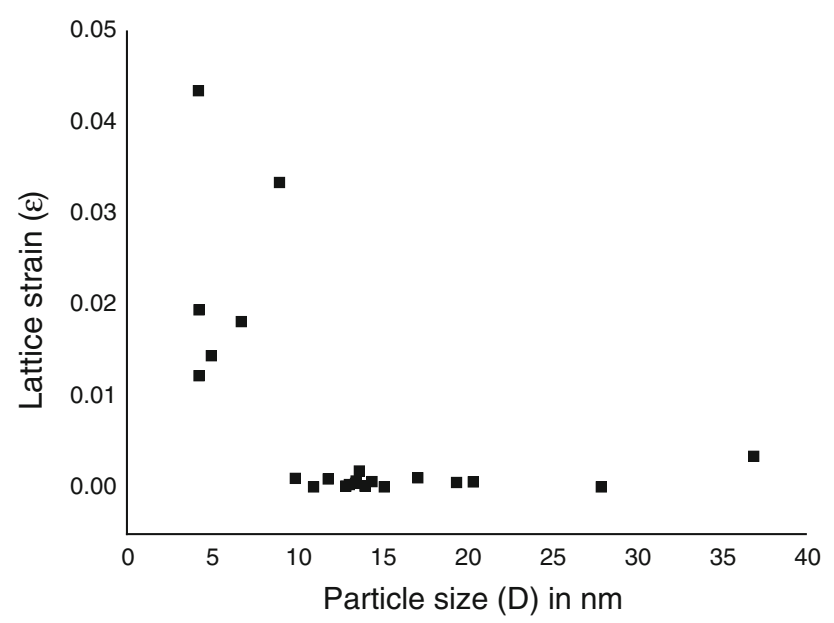

Fig. 9 Plot of lattice strain as function of particle size

oxygen at low partial pressure of oxygen and at elevated temperatures. The electrons formed during this reduction convert $\mathrm{Ce}^{4+}$ to $\mathrm{Ce}^{3+}$ ions and lead to a distortion of the local symmetry. This changes the $\mathrm{Ce}-\mathrm{O}$ bond length and overall lattice parameter. It has been observed that the lattice strain decreases with an increase in particle size. In large crystallites, the loss of few oxygen atoms does not produce much strain and therefore, the lattice distortion observed is less; whereas in case of smaller crystallites, the loss of even one oxygen atom causes very high strain [20, 21].

Lattice strain of the ceria samples prepared under different optimisation conditions was calculated by plotting 4 $\sin \theta$ along $\mathrm{X}$-axis and $\beta_{h k l} \cos \theta$ along Y-axis. The calculated strain values are correlated with average crystallite size in Fig. 9. From Fig. 9, it can be observed that particles with average size between 10 and $37 \mathrm{~nm}$ have less characteristic strain. This indicates that when nanoceria has high crystallinity, the strain and strain-induced relaxation can be reduced. However, samples with particle size below $10 \mathrm{~nm}$ calcined at $400{ }^{\circ} \mathrm{C}$ have characteristic strain. This may arise due to lack of crystallinity as well as the small size effect.

\section{Conclusions}

In summary, coprecipitation of cerium salt solution with ammonia is an excellent method for producing nanocrystalline ceria particles. Both ammonium cerium(IV) nitrate and cerium(III) nitrate hexahydrate yield nanoparticles with size in the range of 4-37 nm. Calcination temperature plays a vital role in the crystallinity of nanoceria particles and calcination temperature of $700{ }^{\circ} \mathrm{C}$ produces highly crystalline particles. Increase in synthetic temperature and molar concentrations of the initial precursors increases the aggregate size of the particles. As concentration of the initial precursor solution increases from 0.1 to $0.3 \mathrm{M}$, average particle size increases to the range of 14.0-20.4 nm. A similar effect was observed with an increase in the temperature of precipitation. As temperature changes from ambient to $70{ }^{\circ} \mathrm{C}$, average crystallite size varies from 6.7-9.9 to $13.4-15.1 \mathrm{~nm}$. Aging of precipitated cerium hydroxide increases the average particle size slightly. Sol-gel process using ethylene glycol solvent results in ceria nanoparticles with higher average particle size of $27.9-36.9 \mathrm{~nm}$. At lower calcination temperature, lattice parameter has values ranging from 5.41 to $5.44 \AA$, but at higher temperature, it is constant at $5.39 \AA$. TG analysis reveals that these oxides are thermally stable from 400 to $873{ }^{\circ} \mathrm{C}$ in chemical composition as well as in crystalline phase. From the SEM image, it can be observed that the microstructure of the ceria crystallites which seem to aggregate to form secondary particles on the surface. Lattice strain analysis using Williamson-Hall analysis indicates that particles with sizes below $10 \mathrm{~nm}$ show characteristic strain.

Acknowledgments Financial support from Kerala State Council for Science, Technology and Environment, India is gratefully acknowledged.

Open Access This article is distributed under the terms of the Creative Commons Attribution License which permits any use, distribution, and reproduction in any medium, provided the original author(s) and the source are credited.

\section{References}

1. Parlak, O., Demir, M.M.: Toward transparent nanocomposites based on polystyrene matrix and PMMA-Grafted $\mathrm{CeO}_{2}$ nanoparticles. ACS Appl. Mater. Interface. 3, 4306-4314 (2011)

2. Karakoti, A.S., Kuchibhatla, S., Suresh Babu, K., Seal, S.: Direct synthesis of nanoceria in aqueous polyhydroxyl solutions. J. Phys. Chem. C 111, 17232-17240 (2007)

3. Garcia, T., Solsona, B., Taylor, S.H.: Nano-crystalline ceria catalysts for the abatement of polycyclic aromatic hydrocarbons. Catal. Lett. 105, 183-189 (2005)

4. Li, X., Li, J., Huo, D., Xiu, Z., Sun, X.: Facile synthesis under near-atmospheric conditions and physicochemical properties of 
hairy $\mathrm{CeO}_{2}$ nanocrystalline. J. Phys. Chem. C 113, 1806-1811 (2009)

5. Rao, K.N., Venkataswamy, P., Reddy, B.M.: Structural characterisation and catalytic evaluation of supported Copper-Ceria catalysts for soot oxidation. Ind. Eng. Chem. Res. 50, 11960-11969 (2011)

6. Reddy, B.M., Bharali, P., Thrimurthulu, G., Saikia, P., Katta, L., Park, S.: Catalytic efficiency of Ceria-Zirconia and Ceria-Hafnia nanocomposites for soot oxidation. Catal. Lett. 123, 327-333 (2008)

7. Sun, C., Li, H., Chen, L.: Nanostructured ceria-based materials: synthesis, properties and applications. Energy Environ. Sci. 5, 8475-8505 (2012)

8. Mai, H., Sun, L.D., Zhang, Y., Si, R., Feng, W., Zhang, H., Liu, H., Yan, C.: Shape selective synthesis and oxygen behaviour of ceria nanopolyhedra, nanorods, and nanocubes. J. Phys. Chem. B 109, 24380-24385 (2005)

9. Li, Y., Sun, Q., Kong, M., Shi, W., Huang, J., Tang, J., Zhao, X.: Coupling oxygen ion conduction to photocatalysis in mesoporousnanorod- like ceria significantly improves photocatalytic efficiency. J. Phys. Chem. C 115, 14050-14057 (2011)

10. Yang, Z., Han, D., Ma, D., Liang, H., Liu, L., Yang, Y.: Fabrication of monodisperse $\mathrm{CeO}_{2}$ hollow spheres assembled by nanooctahedra. Cryst. Growth Des. 10, 291-295 (2010)

11. Cao, C., Cui, Z., Chen, C., Song, W., Cai, W.: Ceria hollow nanospheres produced by a template-free microwave assisted hydrothermal method for heavy metal ion removal and catalysis. J. Phys. Chem. C 114, 9865-9870 (2010)

12. Bumajdad, A., Eastoe, J., Mathew, A.: Cerium oxide nanoparticles prepared in self-assembled systems. Adv. Colloid Interface Sci. 147-148, 56-66 (2009)
13. Winski, F.C., Szpunar, J.A.: The nanocrystalline ceria sol-gel coatings for high temperature applications. J. Sol Gel Sci. Tech. 9, 103-114 (1997)

14. Verma, A., Karar, N., Bakhshi, A.K., Chander, H., Shivaprasad, S.M., Agnihotry, S.A.: Structural, morphological and photoluminescence characteristics of sol-gel derived nano phase $\mathrm{CeO}_{2}$ films deposited using citric acid. J. Nanoparticle Res. 9, 317-322 (2007)

15. Schlupp, M.V.F., Kurlov, A., Hwang, J., Yáng, Z., Döbeli, M., Martynczuk, J., Prestat, M., Son, J.W., Gauckler, L.J.: Gadoliniadoped ceria thin films prepared by aerosol assisted chemical vapour deposition and applications in intermediate-temperature solid oxide fuel cells. Fuel Cells. 13, 658-665 (2013)

16. Hyodo, T., Bieberle-Hutter, A., Hertz, J.L., Tuller, H.L.: Three dimensional arrays of hollow gadolinia-doped ceria microspheres prepared by r.f. magnetron sputtering employing PMMA microsphere templates. J. Electroceramics. 17, 695-699 (2006)

17. Kurian, M, Nair, DS: Effect of preparation conditions on nickel zinc ferrite nano-particles: a comparison between sol-gel auto combustion and co-precipitation methods. J. Saudi Chem. Soc. (2013), http://dx.doi.org/10.1016/j.jscs.2013.03.003

18. Ho, C., Yu, J.C., Kwong, T., Mak, A.C., Lai, S.: Morphologycontrollable synthesis of mesoporous $\mathrm{CeO}_{2}$ nano- and microstructures. Chem. Mater. 17, 4514-4522 (2005)

19. Mote, V.D., Purushotham, Y., Dole, B.N.: Williamson-Hall analysis in estimation of lattice strain in nanometer-sized $\mathrm{ZnO}$ particles. J. Theor. Appl. Phys. 6(6), 2251-7235 (2012)

20. Zhang, F., Jin, Q., Chan, S.: Ceria nanoparticles: size, size distribution, and shape. J. Appl. Phy. 95, 4319 (2004)

21. Deshpande, S., Patil, S., Kuchibhatla, S., Seal, S.: Size dependency variation in lattice parameter and valency states in nanocrystalline ceriumoxide. Appl. Phys. Lett. 87, 133113 (2005) 